\title{
Evaluating the asphalt pavement's surface characteristics by field testing
}

Derya Kaya Ozdemir (Main and Corresponding Author)

Department of Civil Engineering, Faculty of Engineering, Dokuz Eylul University

35390 Izmir (Turkey)

d.kaya@deu.edu.tr

https://orcid.org/0000-0003-1517-9405

\section{Ali Topal}

Department of Civil Engineering, Faculty of Engineering, Dokuz Eylul University

35390 Izmir (Turkey)

ali.topal@deu.edu.tr

https://orcid.org/0000-0002-2601-1926

\section{Bulent Kacmaz}

BSK Construction Company, Folkart Tower, Bayrakli

35540 Izmir (Turkey)

bulentkacmaz@gmail.com

https://orcid.org/0000-0001-8831-3623

\section{Burak Sengoz}

Department of Civil Engineering, Faculty of Engineering, Dokuz Eylul University

35390 Izmir (Turkey)

burak.sengoz@deu.edu.tr

https://orcid.org/0000-0003-0684-4880

Manuscript Code: 15446

Date of Acceptance/Reception: 03.12.2020/17.06.2020

DOI: 10.7764/RDLC.19.3.474

\begin{abstract}
Pavement management systems are crucial because of monitoring the current pavement condition to supply safe, efficient, comfortable and durable riding surface for vehicles. Driving safety is the most important issue, which is closely related to pavement surface texture. The texture of the pavement surface and its ability to resist the polishing effect of heavy traffic is an important parameter in providing necessary skidding resistance during the service life. In this study, 4 different asphalt pavement sections located in Izmir/TURKEY which having different traffic characteristics were investigated every three months for two years aiming to evaluate the effect of traffic volume on the surface textural and frictional properties of the pavement. The textural properties were evaluated using sand patch test (SPT) and a 3D Laser Scanning System (LSS), while Dynamic Friction Tester (DFT) was employed to assess the frictional properties. As a result, lower Mean Texture Depth (MTD) and Mean Profile Depth (MPD) values were obtained for the increased traffic volumes. High correlation was derived between macro and micro textural properties of the asphalt pavement. Additionally, the textural and frictional properties were found highly related for the investigated asphalt pavement surfaces.
\end{abstract}

Keywords: Skid resistance; Friction resistance; Pavement surface texture; Mean texture depth; Mean profile depth.

Pavement design is not only important in terms of construction costs but also plays a major role in safety of users. Increased traffic volume as well as adverse weather affect the textural properties of surfaces negatively, which in turn causes an unsafe driving condition. For the past two decades, road users have been in expectation to have a safe and environmentally friendly roads due to the increased consciousness. National highway authorities are responsible to promote safe driving for the drivers, passengers and pedestrians (Araujo, Bessa, \& Branco, 2015; Li \& He, 2016).Therefore, traffic volume and climate condition should be considered while designing the pavement.

Skid resistance, which is the force developed with the friction values of the pavement surface and the tire of the vehicle, can be classified as the most important surface parameter contributing road safety (Buddhavarapu, Smit, \& Prozzi, 2015; Montella \& Imbriani, 2015). Reduced friction resistance of the pavement surface is directly related with longer braking distance, which can cause serious accidents especially on rainy weather. Based on the significance of the friction value this parameter should be considered both during the design and construction phases and especially controlled regularly during the service life of the road. 
Skid resistance, which is identified as the deviation of a true planar and smooth surface, depends on micro and macro surface texture properties of the pavement (Hu et al., 2016; Kane, Artamendi, \& Scarpas, 2013; Kogbara, Masad, Kassem, Scarpas, \& Anupam, 2016). Microtexture refers to the small scale texture of the pavement aggregate component and it is characterized by wavelengths shorter than $0.5 \mathrm{~mm}$ and peak to peak amplitudes usually between 0.001 and $0.5 \mathrm{~mm}$. On the other hand, macro texture of the pavement refers to the large scale texture and it is characterized by wavelengths between 0.5 and $50 \mathrm{~mm}$ and peak to peak amplitudes usually between 0.1 and $20 \mathrm{~mm}$. Figure 1 demonstrates the macro and micro texture properties of pavement surface (Flintsch, De León, McGhee, \& AlQadi, 2003).

Figure 1. Macro and micro texture properties of pavement surface (Flintsch, De León, McGhee, \& Al-Qadi, 2003).

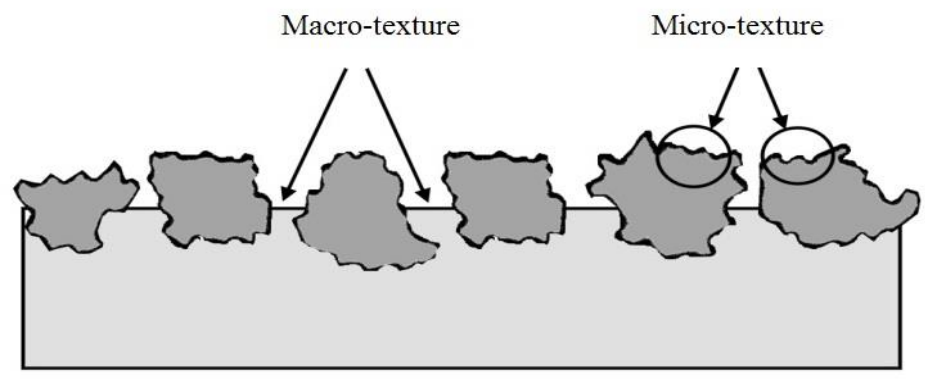

It is possible to say that, macrotexture is affected by gradation and aggregate size while microtexture is by the roughness of the aggregate particles. Friction resistance controls the contact between the tire and the pavement surface and it is generally related to the microtexture of the surface at low vehicle speed (Do, Tang, Kane, \& de Larrard, 2007). Macrotexture of the pavement carries out the drainage of water from the surface, hence it prevents the loss of skid resistance with increasing speed which is very important for traffic safety (Hall et al., 2009). A comprehensive study, conducted by American Association of State Highway and Transportation Officials (AASHTO), indicated that pavement serviceability is related with the roughness of the surface (Sollazzo, Fwa, \& Bosurgi, 2017). For this reason, it is suggested that, pavement surface properties should be monitored regularly during the service life.

Devices, employed for measuring pavement surface frictional resistance, are divided into two groups. The first group consists of the devices which are capable of high speed measurement, while the second group involves the measurement systems at low speed. First group includes methods such as; Full-Scale Tire, Side Force Friction Meter, Variable Slip Technique. On the other hand, Stopping Distance Meter, Deceleration Rate Meter, British Pendulum and Dynamic Friction Tester are the examples of the measurement systems at low speed (Ergun, lyinam, \& lyinam, 2005). Pavement surface texture and skid resistance measurements have always been an interesting topic for researchers. Macrotexture measurement techniques commonly include the following standards: Sand Patch Test (SPT) (ASTM E96596), Outflow Meter Test (ASTM E2380-M-09), and Circular Texture Meter (CTM) (ASTM E2157-01). In recent years, with the advances in computing and laser technologies, new methods have been developed to measure the pavement surface texture. The mini-texture-meter, the Selcom laser system and the noncontact high speed optical scanning technique are the examples of these novel systems, which measure the surface texture with different techniques (Gao, Liu, Wang, Xie, \& Jia, 2019; F. G. Praticò \& Astolfi, 2017; Sengoz, Topal, \& Tanyel, 2012). Previous studies have depicted the relation between the surface texture and skid resistance. Britton et al. investigated the effect of pavement texture between the vehicle tire and the pavement friction. Based on their findings, they concluded that skid numbers (SN) are governed by six texture parameters which depends on the texture size, shape, distribution or spacing (Britton, Ledbetter, \& Gallaway, 1974). Another study, conducted by Hu et al., indicated the effect of differences on microtexture and macrotexture of pavement surfaces on the peak brake coefficients of a standard test tire (Hu et al., 2016). Sengoz et al. (2012) produced calibration curves for 3D Laser Scanning System (LSS) by evaluating average profile depths obtained from the trial pavement segment by using 3D Laser Scanning Systems (LSS) and the Sand Patch Test (SPT) (Sengoz, Topal, \& Tanyel, 2012).

Friction indices have been used in road engineering for years, PIARC sponsored an international friction harmonization study made in 1990. One of the main results of the PIARC experiment was the development of the International Friction Index (IFI). IFI can be defined simply as a statistical model, which describes the correlation between the speed constant and the pavement macrotexture (Fuentes, Gunaratne, de León Izeppi, Flintsch, \& Martinez, 2012).

In this study 4 different flexible pavements, having different traffic volume and heavy vehicle profiles, have been measured every three months for two years to estimate the effects of traffic characteristics on the textural and frictional 
surface of the pavement. The mean profile depth (MPD) and the mean texture depth (MTD) of the pavement surfaces were monitored by employing the 3D LSS and SPT respectively in order to evaluate the texture properties of the pavement surfaces, while the frictional properties were measured by using (DFT).

\section{Materials and Methods}

\section{Experimental}

During the field measurements stage, 3D LSS was utilized to quantify the MPD values based on ASTM E 1845-09 standard, the SPT was applied to measure MTD values based on ASTM E 1845-09 standard and DFT was employed to survey friction indices of the test pavement. All the measurements were done at the similar weather conditions in order to eliminate the weather effect.

\section{D Laser Scanning System (LSS)}

Advances in measuring devices make the measurement techniques faster and more reliable. 3D laser scanning system, developed in recent years, provides scanning and monitoring of macrotexture of the pavement surfaces. Metris Model Maker D100 3D laser scanner with enhanced sensor is designed based on ASTM E 1845-09 standard (Figure 2). This device was employed aiming to examine the full range of colors and depths on asphalt pavement surfaces.



The system includes a 6-axis tool holder, a line laser scanner, data collecting system, and a built-in USB output to transfer scanned data to the portable computer in order to execute additional processing by software package which accompanies the device to give out MPD values. The MPD values can be computed from a sample baseline divided into two equal halves as presented in Figure 3. The following equation presents the computation of MPD value.

$$
M P D=\frac{\text { Peaklevel }(1 s t)+\operatorname{Peaklevel}(2 n d)}{2}
$$

Figure 3. Standard method used for calculating MPD (ISO 13473-1).




The laser scanner adapts the laser power to match the surface characteristics of pavement with enhanced scanning performance. During the scanning process, the laser device automatically controls the changes in surface conditions based on the color and reflectivity of the bitumen, based on the results, it adjusts the laser power and sensor settings accordingly.

\section{Sand Patch Test (SPT)}

Sand Patch Test (SPT) (ASTM E 965, 96), has been historically used as the main technique for measuring pavement macrotexture (Uz \& Gökalp, 2017). The principle is fairly obvious, greater texture will require more sand to be taken up and smaller circle will be achieved from the standard quantity of sand. The texture depth of the surface on which the SPT is performed, is represented by MTD value. $25 \mathrm{~mm}^{3}$ of fine glass beads (75 $\mu \mathrm{m}$ in dimensions) are spread over cleaned surface in order to form a circle. The average diameter of the circle is measured in order to calculate the MTD values by using the Equation 2. The test results are effected by weather conditions, granulometer diversity or the shape of glass beads etc. (Choubane, 2007).

$$
A v g \cdot M T D=\frac{4 V}{\Pi D^{2} a v g}
$$

$$
\begin{aligned}
& \text { Where; } \quad \mathrm{V}=\quad \text { Volume of glass spheres, } \mathrm{mm} 3 \\
& \mathrm{D}_{\mathrm{avg}}=\quad \text { Average diameter of the circles, } \mathrm{mm}
\end{aligned}
$$

\section{Dynamic Friction Tester (DFT)}

The DFT is a portable instrument for measuring pavement surface friction as a function of the speed under various conditions. The instrument is comprised of a measuring unit and a control unit; $x-y$ plotter which can be used to record data and a water tank that is used in order to administer water at speed of $3.6 \mathrm{l} / \mathrm{min}$. Electronic devices are employed to determine rotational speed, rotational torque, and downward load. The measuring unit consists of a disc made to rotate horizontally at a specified velocity ( 5 to $89 \mathrm{~km} / \mathrm{h}$ ) before being lowered onto a wetted test surface for measurement of friction. A relationship graph between the speed and the friction can be plotted by using the data recorded at $20,40,60$, and $80 \mathrm{~km} / \mathrm{h}$. Figure 4 presents the segments of the DFT device. Friction at $20 \mathrm{~km} / \mathrm{h}$ is usually taken into account for evaluation purposes and recorded as DFT20 value.

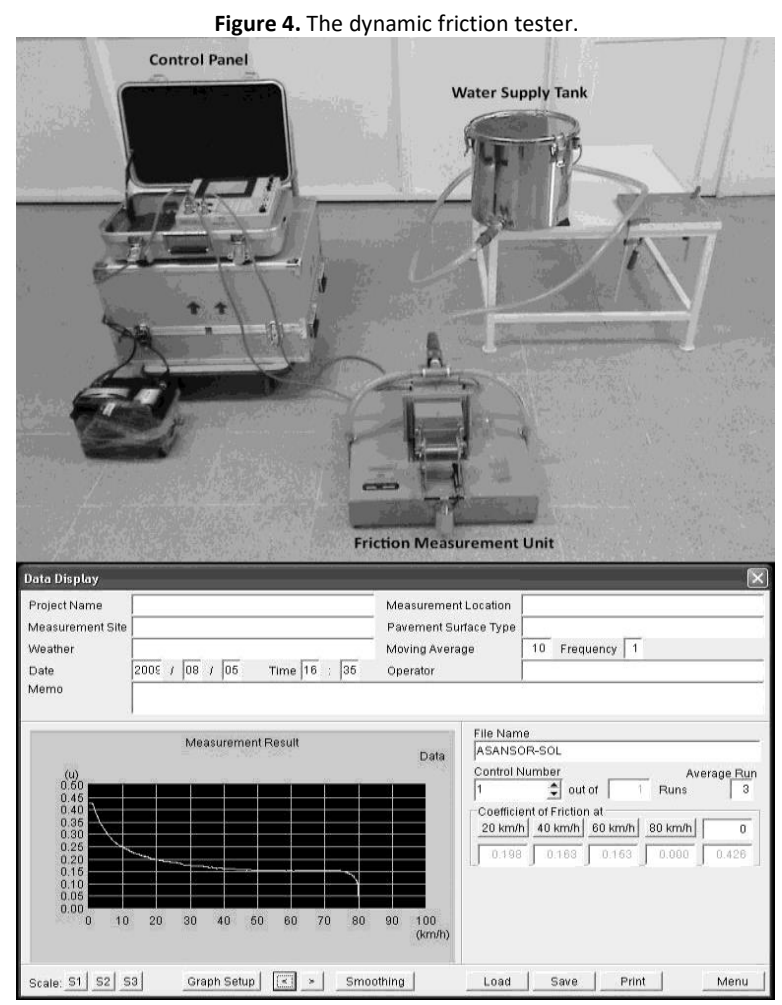




\section{Selection of Station Points}

Considering the condition of the pavement surfaces and the probability of gathering continuous data, attention was paid to select different station points in Izmir/Turkey. The observation points, which should be critical in terms of traffic safety, were determined by the General Security Directorate of Izmir based on traffic accident reports. In the scope of this study, four different station points with similar flexible pavements (dense graded hot mix asphalt) were selected named as; Karsiyaka Tunnels, Kisikkoy, Yesildere Street and Ankara Street. Figure 5 presents a general view of the location of the investigated test pavement sections.

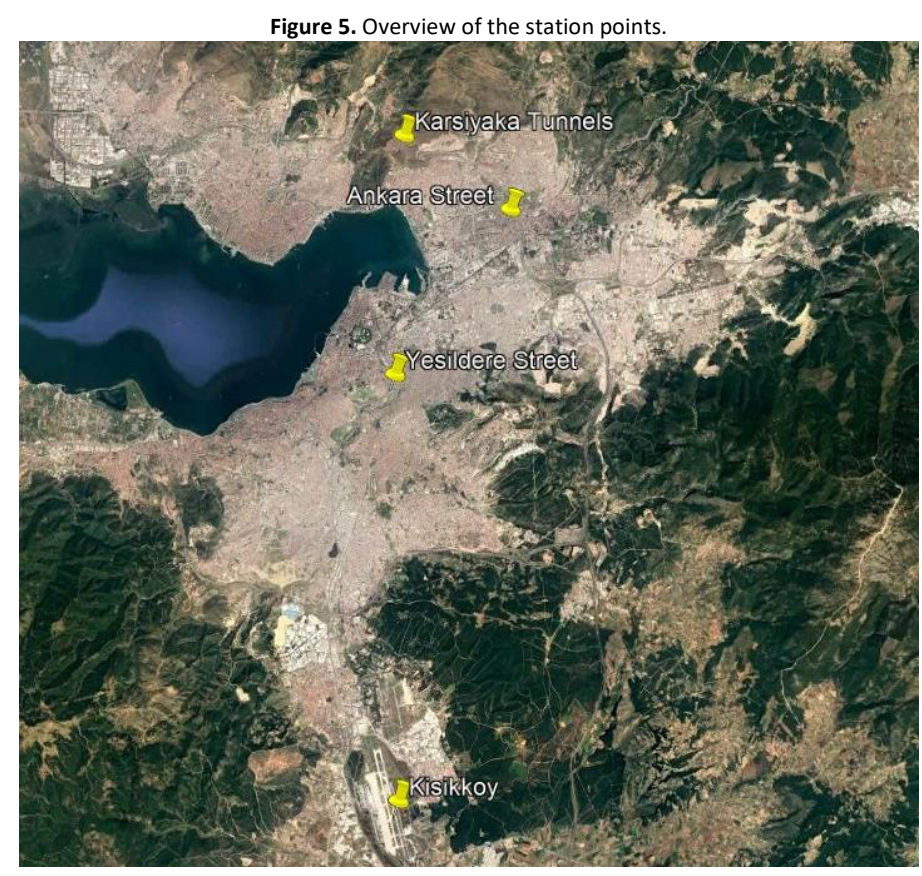

The first observation point, Karsiyaka Tunnels, is located at the North of Izmir with 3 lanes at each direction and has been in service since 2007. Yesildere Street is about $4.5 \mathrm{~km}$ long, $25 \mathrm{~m}$ wide and provides the traffic from North side to Westside of the city. Ankara Street is a multilane divided road (2x3), which is about $6.7 \mathrm{~km}$, and connects Izmir to the eastern side of Turkey. Kisikkoy is a highway having four lane (two ways for each direction) with $15 \mathrm{~m}$ wide. Figure 6 presents the detailed investigated sections with asphaltic overlays.



(a) Karsiyaka Tunnels

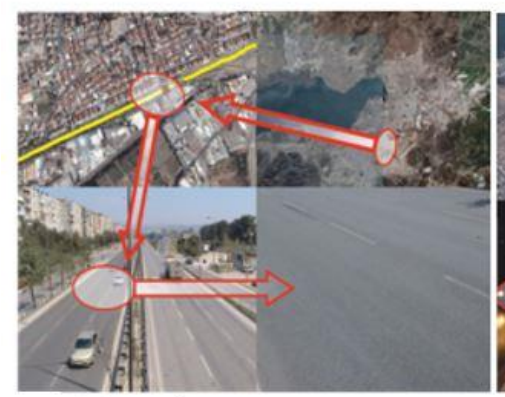

(c) Ankara Street

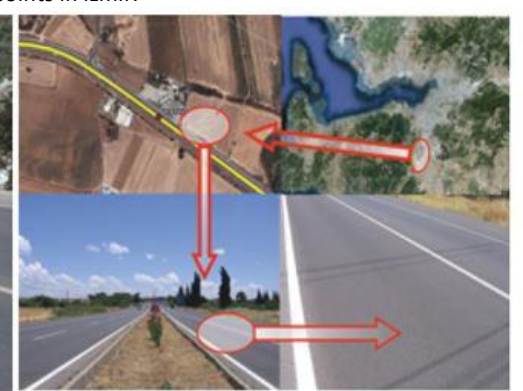

(b) Kisıkkoy

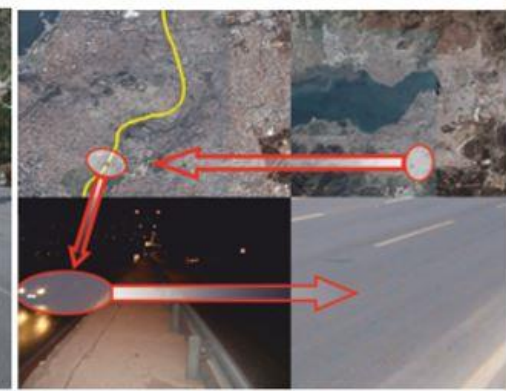

(d) Yesildere Street 
Detailed traffic observations were made on the test sections via video camera. The types of vehicles were converted to passenger car unit. The cumulative values were taken into account for every 3 months. Figure 7 depicts the cumulative traffic volume (CTV) values of all observations points in terms of passenger car unit.

As seen in Figure 7, Yesildere Street has the highest CTV value among all observation points, while Karsiyaka Tunnels has the lowest one. Each test pavement has been manufactured with hot mix asphalt (HMA) wearing course with the aim of serving different level of service. The material properties of the pavements; such as bitumen properties and aggregate gradation, are the same for all station points, which ensure the possibility of accurate comparison. The type of the aggregate is limestone and chosen in conformity with the Type I wearing course of Turkish Specifications. The bitumen with 50/70 penetration grade supplied from Izmir Aliaga Petroleum Refinery was used as a binding material. The physical properties of the aggregate and the bitumen belonging to each station points are presented in Table 1-2 respectively.

Figure 7. Traffic volume $(\mathrm{v} / \mathrm{h})$ versus measurement period per each station point.

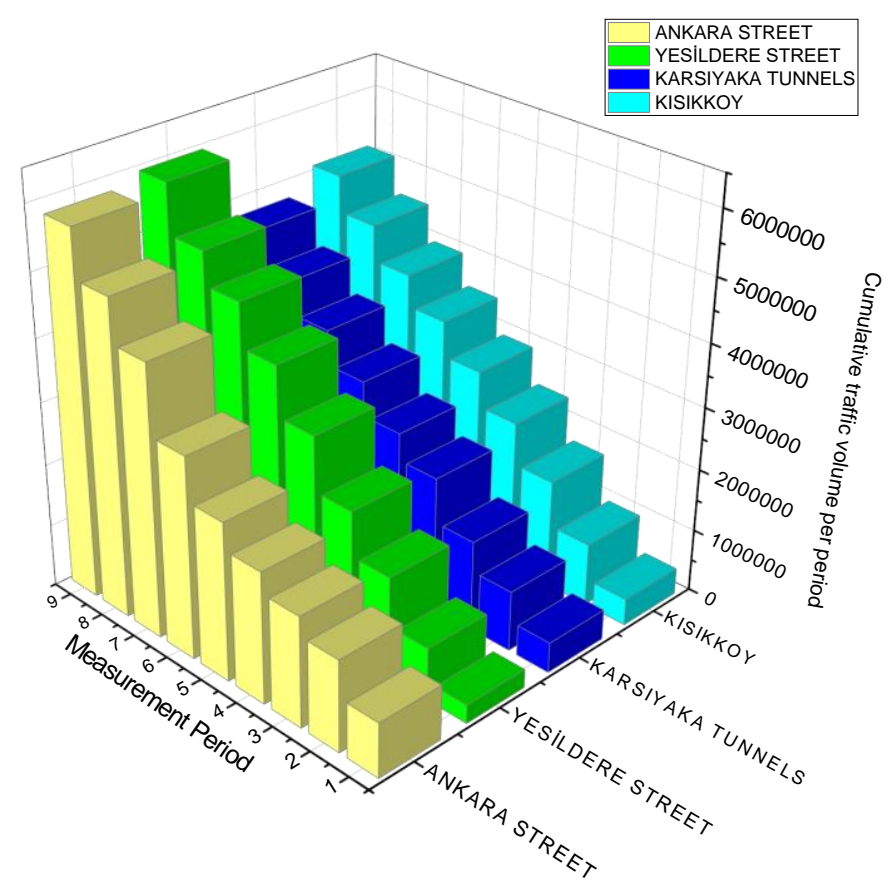

Table 1. Properties of limestone aggregates.

\begin{tabular}{ccc}
\hline Test & Specification & Specification limits \\
\hline Specific Gravity (Coarse Agg.) & ASTM C127 & - \\
Bulk & - \\
SSD & & - \\
Apparent & & \\
\hline Specific Gravity & - \\
(Fine Agg.) & ASTM C128 \\
Bulk & & - \\
SSD & & - \\
Apparent & & max. 45 \\
\hline Specific Gravity (Filler) & max. 10 \\
\hline Los Angeles Abrasion (\%) & ASTM C 131 & min. 40
\end{tabular}




\begin{tabular}{clc}
\hline Test & \multicolumn{1}{c}{ Specification } & Specification limits \\
\hline $\begin{array}{c}\text { Penetration } \\
\left(25^{\circ} \mathrm{C} ; 0.1 \mathrm{~mm}\right)\end{array}$ & ASTM D5, EN 1426 & $50-70$ \\
\hline Softening Point $\left({ }^{\circ} \mathrm{C}\right)$ & ASTM D36, EN 1427 & $46-54$ \\
\hline Viscosity at $\left(135^{\circ} \mathrm{C}\right)-$ Pa.s & ASTM D4402 & - \\
\hline $\begin{array}{c}\text { Thin Film Oven Test }(\mathrm{TFOT})\left(163^{\circ} \mathrm{C} ; 5 \mathrm{~h}\right) \\
\text { Change of Mass (\%) }\end{array}$ & ASTMD1754, EN 12607-1 & 0.5 (max.) \\
\hline Retained Penetration after TFOT (\%) & ASTM D5, EN 1426 & - \\
\hline Softening Point Diff. after TFOT $\left({ }^{\circ} \mathrm{C}\right)$ & ASTM D36, EN 1427 & 48 (min) \\
\hline Ductility $\left(25^{\circ} \mathrm{C}\right)$-cm & ASTM D113 & - \\
\hline Flash Point $\left({ }^{\circ} \mathrm{C}\right)$ & ASTM D92, EN 22592 & 230 (min) \\
\hline
\end{tabular}

MTD values of the investigated test sections obtained by SPT and MPD values obtained by LSS are presented in Figure 8 and Figure 9 respectively.

Figure 8. MPD values for all station points' pavement during measurement periods.
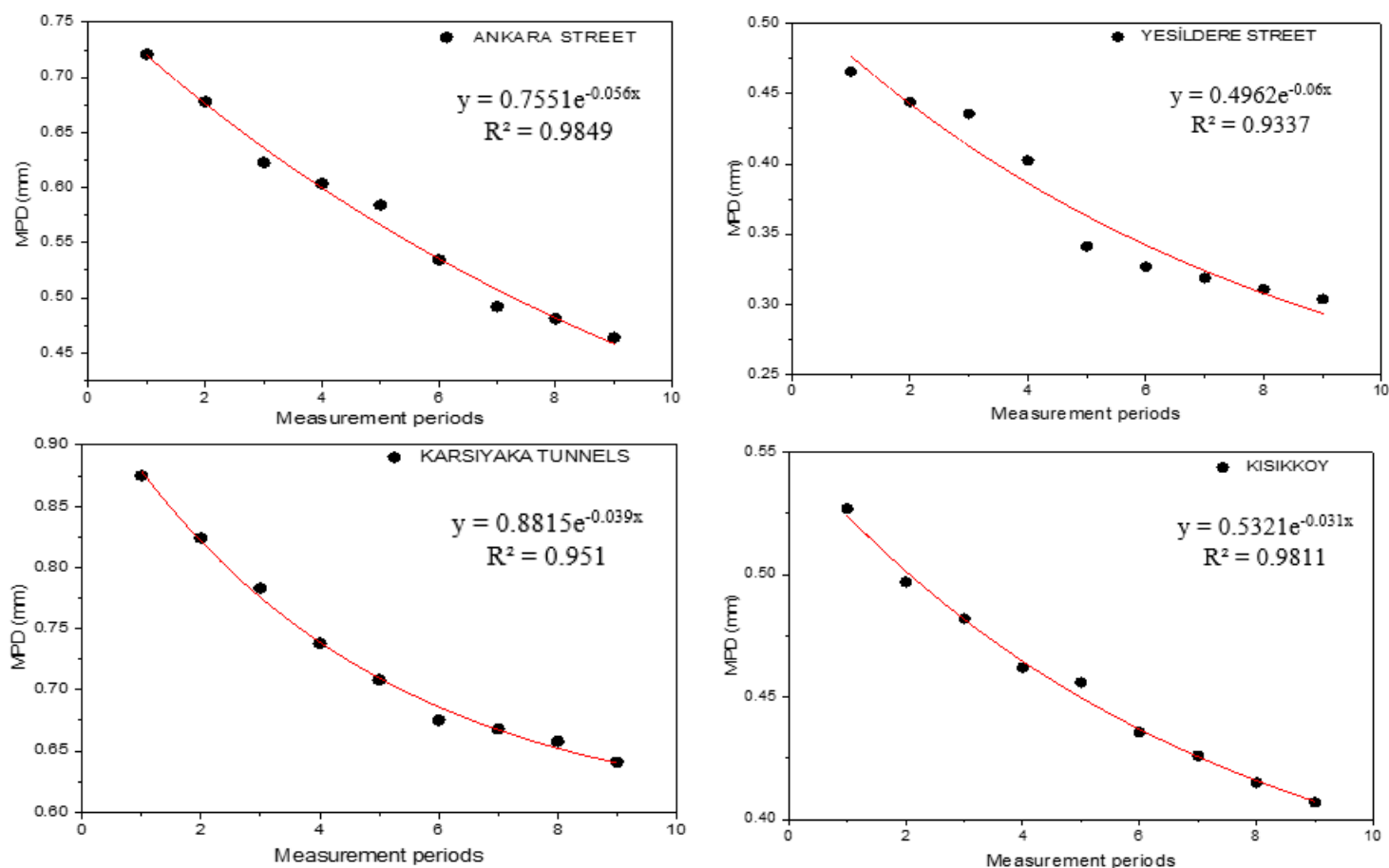

Based on the results, the decrease in the MPD and the MTD values were depicted throughout the measurement periods. The trend lines were drawn exponentially and regression coefficient together with equations, which shows the correlation between the axis, are presented on the graphs. The minimum decrease of MTD (30\%) and MPD (33\%) values were observed at Kisikkoy station. This result can be clarified by having the most oxidized pavement surface because Kisikkoy is the oldest station point among the others in terms of service life. The maximum decrease (57\% for MTD, 37\% for MPD) was obtained at Yesildere Street. This can be explained by the increased cumulative traffic volume. The more the cumulative traffic volume the more the abrasion of the surface which results in decreased MTD and MPD values. In order to evaluate this effect, the variation of MPD values (the percentage of the MPD value corresponding to measurement period to initial value) together with CTV rate (the ratio of the cumulative CTV value corresponding to measurement period to initial value) were drawn (Figure 10-a). Figure 11-a indicates that the higher increment in CTV values resulted in higher drop in MPD rate in the same manner as in CTV values. The MPD variation and CTV rate were investigated again together in Figure 10-b. As seen from Figure 10-b, these two values were highly correlated with each other $\left(R^{2}=0.96 \sim 0.99\right)$ for test stations. 
Figure 9. MTD values for all station points' pavement during measurement periods.
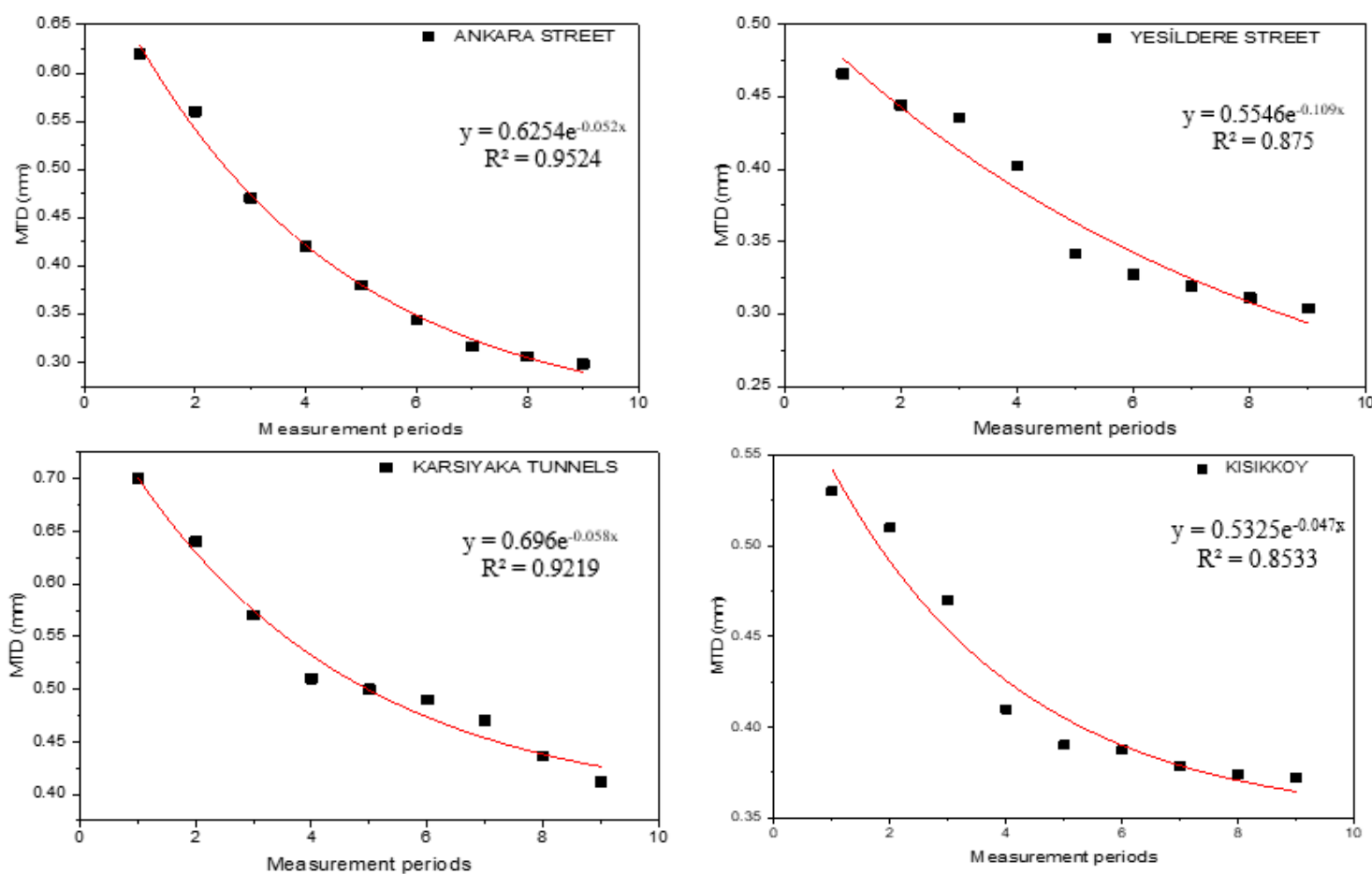

(a)

(b)
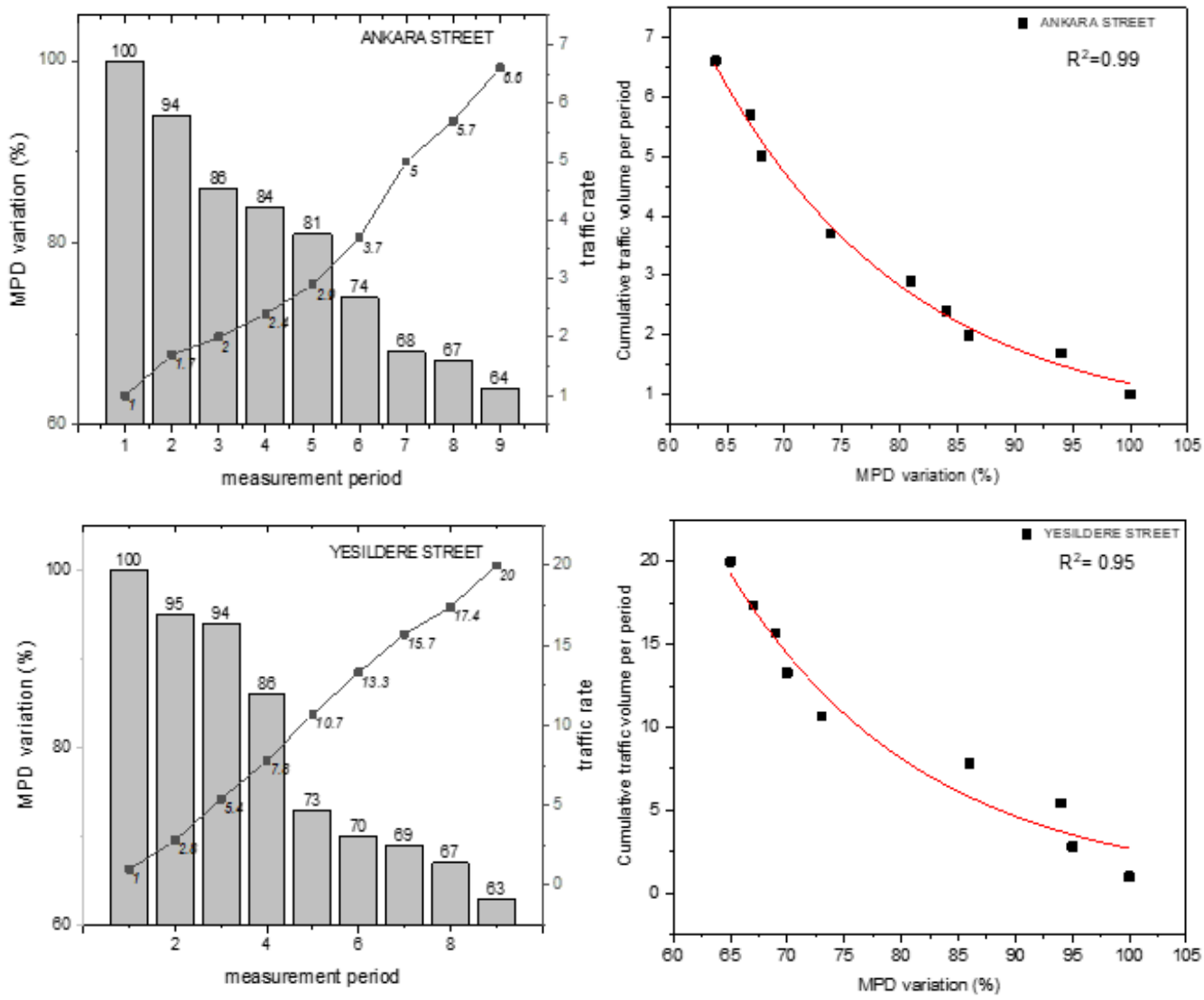

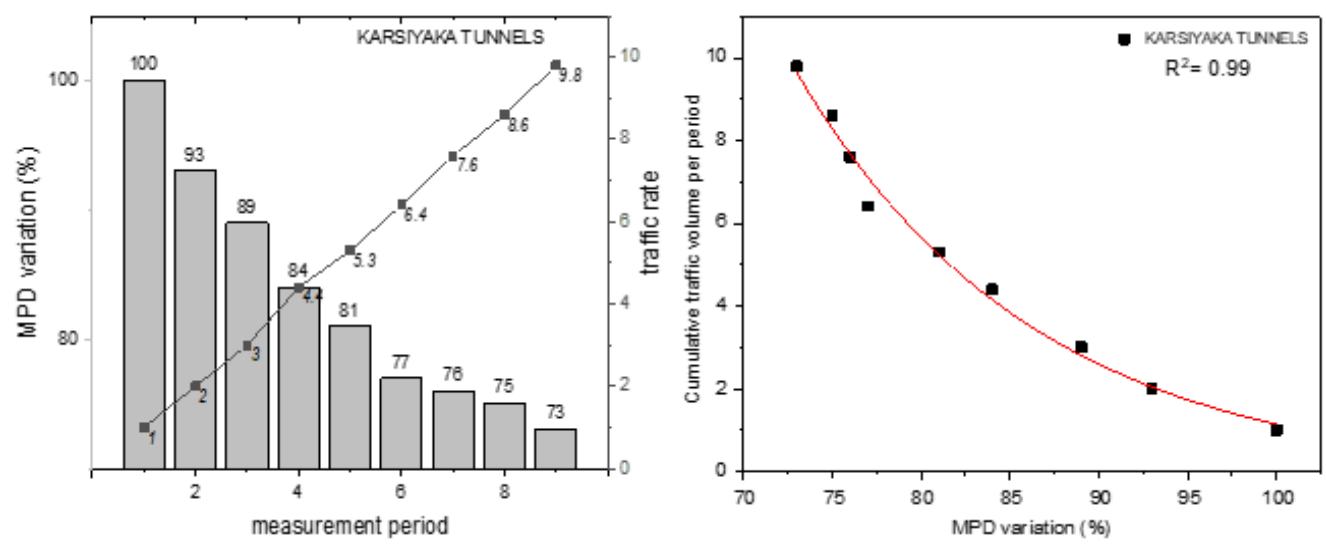

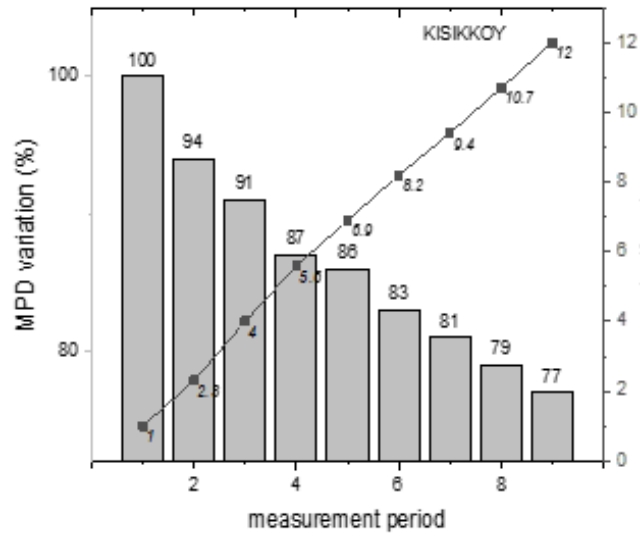

(a)

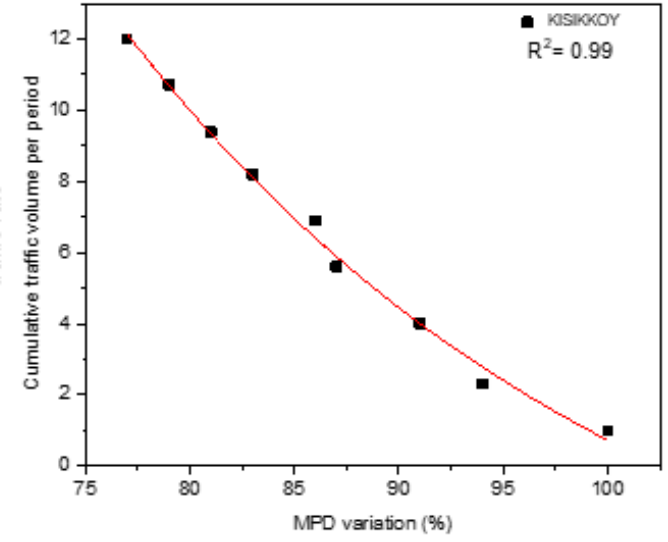

(b)

Additionally, MTD and MPD values were plotted together in Figure 11 for each station points in order to develop a correlation between these two parameters. High coefficient of correlation revealed a strong relation $\left(R^{2}=0.89^{\sim} 0.97\right)$ between MTD and MPD values for all station points. Past studies have also revealed similar results (Abe, Tamai, Henry, \& Wambold, 2001; Hanson \& Prowell, 2004; Praticò \& Vaiana, 2015; Sengoz, Topal, \& Tanyel, 2012).

The relation between the frictional and textural characteristics of the station points were investigated by evaluating the MPD and DFT(20) values as depicted in Figure 12.


The results have shown that, there is a strong correlation between the MPD values and DFT(20) values of each station $\left(R^{2}=0.90^{\sim} 0.97\right)$. This result indicates that, the better the textural characteristics, the better the frictional characteristics of the asphalt pavement.

Lastly, the coefficient of determination belongs to the all abovementioned parameters are given in Table 3, in order to analyze the relationship between the surface texture and traffic characteristics. As depicted in Table 3, all the coefficient of determinations are between $0.85^{\sim 0.99}$, which means surface texture parameters and traffic characteristics are highly correlated with each other.

Table 3. The coefficient of determinations.

\begin{tabular}{ccccc}
\hline & Table 3. The coefficient of determinations. & & & \\
& & Yesildere \\
& Ankara Street & Street & Karsiyaka Tunnels & Kisikkoy \\
\hline Measurement Period-MTD & 0.95 & 0.88 & 0.92 & 0.85 \\
\hline MTD-MPD & 0.95 & 0.89 & 0.97 & 0.91 \\
\hline Measurement Period-MPD & 0.98 & 0.93 & 0.95 & 0.98 \\
\hline CTV-MPD & 0.99 & 0.95 & 0.99 & 0.99 \\
\hline DFT20-MPD & 0.90 & 0.97 & 0.97 & 0.92 \\
\hline
\end{tabular}

\section{Conclusions and Recommendations}

Asphalt pavement surface properties were evaluated on similar flexible pavement sections by employing the 3D Laser Scanner, the Sand Patch and Dynamic Friction Tests. Major findings of this study can be shown as below:

- MPD and MTD values of each station were decreased between (33 37\% for MPD) and (30 57\% for MTD) throughout the measurement periods due to the increased cumulative traffic. It is concluded that, traffic volume and the service life of the pavement is directly related with the textural characteristics of the asphalt pavement. 
- The higher increment in CTV values resulted in higher drop in MPD rate throughout the measurement period. The MPD variation and CTV rate of the asphalt pavement are highly correlated $\left(R^{2}=0.96 \sim 0.99\right)$.

- There is a reasonable linear correlation between the MPD and MTD values of the asphalt pavement $\left(R^{2}=0.89 \sim 0.97\right)$.

- MPD values are interpreted together with DFT(20) values within the scope of this study. Based on the results, a high linear correlation existed between MPD and DFT(20) values $\left(R^{2}=0.90 \sim 0.97\right)$.

- Overall, there are clear evidences about the relation between the frictional and textural characteristics of the asphalt pavement. However, only dense graded hot mix asphalt applications were investigated within the scope of this study, however, there are more pavement types like stone mastic asphalt, porous asphalt etc. can be investigated.

Acknowledgement

This research was sponsored by the Scientific and Technological Research Council of Turkey (TUBITAK) under the project number 108M293 for which the authors are greatly indebted. Also; the authors would like to thank Dokuz Eylul University, Graduate School of Natural and Applied Sciences.

References

Abe, H., Tamai, A., Henry, J., \& Wambold, J. (2001). Measurement of pavement macrotexture with circular texture meter. Transportation Research Record, 1764(1), 201-209.

Araujo, V. M., Bessa, I. S., \& Branco, V. T. C. (2015). Measuring skid resistance of hot mix asphalt using the aggregate image measurement system (AIMS). Construction and Building Materials, 98, 476-481.

Britton, S., Ledbetter, W., \& Gallaway, B. (1974). Estimation of skid numbers from surface texture parameters in the rational design of standard reference pavements for test equipment calibration. Journal of Testing and Evaluation, 2(2), 73-83.

Buddhavarapu, P., Smit, A. F., \& Prozzi, J. A. (2015). A fully Bayesian before-after analysis of permeable friction course (PFC) pavement wet weather safety. Accident Analysis \& Prevention, 80, 89-96.

Choubane, B. (2007). Pavement Surface Condition/performance Assessment: Reliability and Relevancy of Procedures and Technologies: ASTM International.

Do, M.-T., Tang, Z., Kane, M., \& de Larrard, F. (2007). Pavement polishing-Development of a dedicated laboratory test and its correlation with road results. Wear, 263(1-6), 36-42.

Ergun, M., Iyinam, S., \& lyinam, A. F. (2005). Prediction of road surface friction coefficient using only macro-and microtexture measurements. Journal of transportation engineering, 131(4), 311-319.

Flintsch, G. W., De León, E., McGhee, K. K., \& Al-Qadi, I. L. (2003). Pavement surface macrotexture measurement and applications. Transportation Research Record, 1860(1), 168-177.

Fuentes, L. G., Gunaratne, M., de León Izeppi, E., Flintsch, G. W., \& Martinez, G. (2012). Determination of pavement macrotexture limit for use in International Friction Index model. Transportation Research Record, 2306(1), 138-143.

Gao, L., Liu, M., Wang, Z., Xie, J., \& Jia, S. (2019). Correction of texture depth of porous asphalt pavement based on CT scanning technique. Construction and Building Materials, 200, 514-520.

Hall, J., Smith, K. L., Titus-Glover, L., Wambold, J. C., Yager, T. J., \& Rado, Z. (2009). Guide for pavement friction. Final Report for NCHRP Project, $1,43$.

Hanson, D. I., \& Prowell, B. D. (2004). Evaluation of circular texture meter for measuring surface texture of pavements. National Center for Asphalt Technology Report (04-05), The Center.

Hu, L., Yun, D., Liu, Z., Du, S., Zhang, Z., \& Bao, Y. (2016). Effect of three-dimensional macrotexture characteristics on dynamic frictional coefficient of asphalt pavement surface. Construction and Building Materials, 126, 720-729.

ISO. (1997). Characterization of pavement texture by use of surface profiles - Part 1: Determination of mean profile depth. Standard No. 13473-1, International Organization for Standardization, Geneva, Switzerland.

Kane, M., Artamendi, I., \& Scarpas, T. (2013). Long-term skid resistance of asphalt surfacings: correlation between Wehner-Schulze friction values and the mineralogical composition of the aggregates. Wear, 303(1-2), 235-243.

Kogbara, R. B., Masad, E. A., Kassem, E., Scarpas, A. T., \& Anupam, K. (2016). A state-of-the-art review of parameters influencing measurement and modeling of skid resistance of asphalt pavements. Construction and Building Materials, 114, 602-617.

Li, P., \& He, J. (2016). Geometric design safety estimation based on tire-road side friction. Transportation Research Part C: Emerging Technologies, $63,114-125$.

Montella, A., \& Imbriani, L. L. (2015). Safety performance functions incorporating design consistency variables. Accident Analysis \& Prevention, 74, 133-144.

Praticò, F. G., \& Astolfi, A. (2017). A new and simplified approach to assess the pavement surface micro-and macrotexture. Construction and Building Materials, 148, 476-483. 
Praticò, F., \& Vaiana, R. (2015). A study on the relationship between mean texture depth and mean profile depth of asphalt pavements. Construction and Building Materials, 101, 72-79.

Sengoz, B., Topal, A., \& Tanyel, S. (2012). Comparison of pavement surface texture determination by sand patch test and 3D laser scanning. Periodica Polytechnica Civil Engineering, 56(1), 73-78.

Sollazzo, G., Fwa, T., \& Bosurgi, G. (2017). An ANN model to correlate roughness and structural performance in asphalt pavements. Construction and Building Materials, 134, 684-693.

Standard practice for calculating pavement macrotexture mean profile depth, ASTM E 1845-09. (2009). ASTM International, Vol. 04.03, West Conshohocken, Pennsylvania West Conshohocken, PA. USA.

Standard test method for measuring pavement macrotexture depth using a volumetric technique, ASTM E 965-96. (2006). ASTM International, Volume 04.03, West Conshohocken, Pennsylvania West Conshohocken, PA, USA.

Standard test method for measuring pavement macro-texture properties using the circular track meter, ASTM E 2157-01. (2005). American Society for Testing Materials, Pennsylvania, USA.

Standard test method for measuring pavement texture drainage, using an outflow meter, ASTM E 2380. (2009). American Society for Testing Materials, Pennsylvania, USA.

Uz, V. E., \& Gökalp, İ. (2017). The effect of aggregate type, size and polishing levels to skid resistance of chip seals. Materials and Structures, 50(2), 126 